\title{
Towards the New Concept of Smart Roads: Regulatory Framework and Emerging Projects Overview
}

\author{
Simone Franzò, Vito Manfredi Latilla, Michela Longo \\ Dept. Of Energy and Management, Economics and \\ Industrial Engineering \\ Politecnico di Milano \\ Milan, Italy \\ simone.franzo@polimi.it; vito.manfredilatilla@polimi.it \\ michela.longo@polimi.it
}

\author{
Stefano Bracco \\ Department of Naval, Electrical, Electronics and \\ Telecommunication Engineering \\ University of Genoa - Savona Campus, Italy \\ stefano.bracco@unige.it
}

\begin{abstract}
The evolution of the transportation sector enabled by the diffusion of smart roads represent a valuable opportunities for all the stakeholders involved, starting from and users (i.e. drivers) themselves and companies at the different stages of the value chain. Such evolution is driven not only by technology development, but also by the regulatory framework at national and supranational level. The analysis of some first experiences related to the implementation of smart roads concepts shows a certain level of heterogeneity among analyzed projects, none of them realized in Italy. In order to exploit such an opportunity, the Italian regulatory framework regarding transportation systems in Italy has been analyzed. It emerges that some improvements are required compared to the European context, e.g. the definition of technological standards.
\end{abstract}

Keywords-Smart road; Intelligent Transport Systems; regulation;

\section{INTRODUCTION}

The evolution of the transportation sector is a critical factor to enable a sustainable, green, smart and inclusive economic growth, creating road infrastructures that are agile, efficient, safe, affordable, reliable and easy to access [1 - 4]. This would help facilitate not only the mobility and transport of people, but also of goods, favoring the growth of the industrial system and providing a better logistic to the commercial goods. With this regard, technology may be adopted and deployed throughout the utilization phases of the road transportation infrastructure [5 - 7]. As an example, the evaluation of road infrastructure status and condition enables a more effective planning of the maintenance activities and the investment required, favoring the construction of more efficient infrastructures, both in terms of capital investment and life span of the infrastructures themselves [8 $10]$.

Over the last few years, the use of the term "smart" has become a widespread practice at all levels. Even roads, therefore, need to transform themselves in order to play a relevant role in this smart revolution [11]. The road sector, indeed, faces a major challenge for this century: the definition of a new paradigm that makes Smart Roads a reality [12].

The digital transformation of the road infrastructures may represent a trigger for the entire economy of a country, since the infrastructural sector, being a capital intensive one, is able to generate huge amount of investment and support the growth of all the value chain, linking together different players of the economy, hence boosting economic growth, specifically operating at the frontier of the technology development [13 - 18]. Focusing on Italy, this is therefore a great chance for the economic development of the country. Indeed, it allows to shed new light of the existing infrastructure, which will be updated through the adoption of digital solutions and interfaces [19]. Such technological upgrade comes at a much lower cost than the building of a completely new infrastructure, hence it is so far more convenient and affordable; furthermore, the technological upgrade allows the deployment of smart solutions for transportation as well as new services for customers, either private users or companies transporting goods for logistic purposes [20 - 25].

Technology increases the options available to the decision makers to better define transportation policies and the management of congestions and traffic. Moreover, technology improves the customer experience (i.e., for final users), offering digital services related to the deployment of a smart infrastructure which can provide ad hoc services to the customers [26 - 30]. For companies, digitalization of the infrastructure means a higher security for their goods, better tracking systems, less administrative procedures, personalized services and solutions along all the value chain, improving logistics and favoring the diffusion of new and innovative solutions.

With reference to the know-how related to the road transportation sector, the Italian industrial system has important competitive advantages thanks to the quality of the technologies and solutions developed by the Italian companies active in the transportation sector, therefore the development of smart solutions for road transportation may favor the research and development of all the value chain that works with the transportation infrastructure, and hence the growth of the Italian industry.

Considering all the aforesaid, smart road has become a research hotspot specifically among practitioners, but the research mainly concentrates on some single smart functions of roads or some specific technologies such as snow-melting, solar 
energy harvesting, etc., with no explicit definition or integrated framework for smart roads [31].

On the other hand, the necessity of rethinking the road system by adopting smart solutions is in the agenda of the policy makers, both at national and European level. Nevertheless, the planning of intervention on such system is delayed by the high fragmented and jeopardized scenario that characterize the infrastructure system itself, where several rules, regulations, administrative bodies and procedures hinder the adoption of innovative solutions. Therefore, in the next section of the paper, the European and Italian Regulatory frameworks on the transportation systems regulation is analyzed.

\section{THE REGULATORY FRAMEWORK}

On top of the laws and regulations of each country and of the European union, there are the rules that apply specifically to the technologies adopted at infrastructure level. At European level, the cornerstone of the regulation ruling this sector is the Directive 2010/40/UE1, which aims to favor the development and deployment of innovative technologies to boost the diffusion of an Intelligent Transportation System (ITS), introducing specific business standards common to all the European countries [32]. The aim is to develop a unique European ground for the transportation system, to make such system more efficient, cost-effective and convenient for the users, leaving space to the single European countries to define on which specific technologies to invest.

The Directive 2010/40/UE has established a framework to favor the diffusion and the utilization of ITS in the road transport sector at European level, defining the following investment priorities:

1. Optimal use of data and information relevant to streets, traffic and cargo transportation (transport of goods);

2. Homogeneity in the development of the services related to ITS and to the traffic management infrastructure;

3. Adoption of ITS for the safety of streets' users and for the security of goods transported;

4. Connections among vehicles and the road infrastructures.

In line with the above priorities, the Directive 2010/40/UE states the following:

a. To provide in all the European territory all the information services related to the intermodal mobility;

b. To provide in all the European territory the real time traffic information system;

c. To provide a minimum free standard of information to all roads' users;

d. To provide a unique and common standard for emergency call (eCall) at European level;

e. To provide information services for safe parking areas for trucks and commercial vehicles in general;

f. To provide reservation services for safe parking areas for trucks and commercial vehicles in general.
Following the aforesaid items, the European Commission has issued the Rules 962/2015, 886/2013, 305/2013 e 885/2013 which provide the specifications to be adopted to implement points b., c., d., and e. mentioned above [32].

Despite the fact that the ITS were already considered as relevant measures to increase the quality of the transportation system and of the logistic services in the Italian "Masterplan for the Transportation and Logistics" of 2001, and that the "Guidelines for the transportation and Logistics" of 2007 recognized to the ITS a central role for the achievement of efficiency, safety and sustainable goals in the mobility, only the Italian Law no. 221/2012 has transferred in the Italian regulatory systems the provisions of the EU Directive 2010/40/UE. The Italian law 221/2012, indeed, defines the ways according to which the ITS shall be developed and deployed at national level, establishing, with the Decree 02/2013 for the Diffusion of Smart Transportation Systems, the following:

1. the requirements for the diffusion of ITS;

2. actions required to favor the diffusion of ITS at national level;

3. sectors of intervention;

4. continuous operation of the ITS services for traffic and logistics;

5. telematic datacenter with the list of all the vehicles and ITS applications for safety (eCall);

6. connection between vehicles and infrastructure;

7. ComITS - Team for coordinating the initiatives regarding the adoption of ITS.

Lastly, the Decree no. 446/2014 has stated that the Minister for the Infrastructure and Transportation has the responsibility to adopt the "National Plan for the development and adoption of ITS".

Figure 1 describes the list of regulations, plan actuated with European Union (EU).

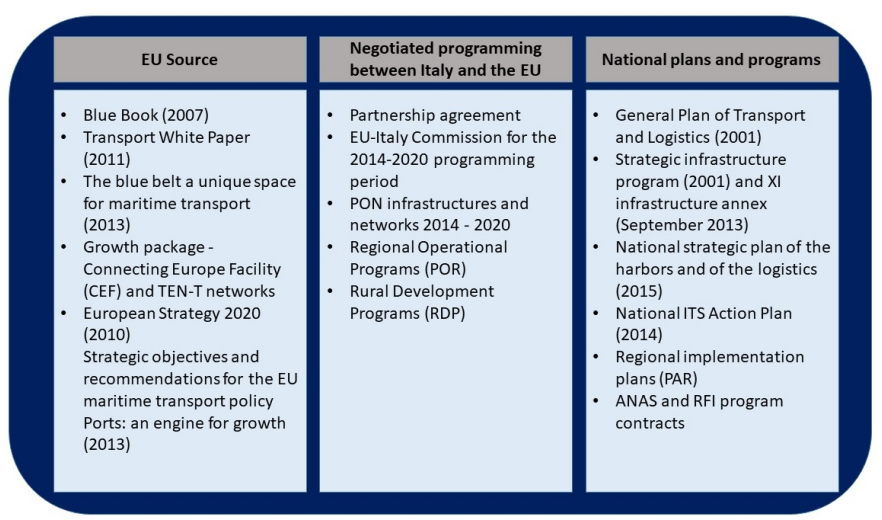

Fig. 1. List of regualations and plans with EU.

\section{SMART ROADS IMPLICATIONS ON INVOLVED STAKEHOLDERS}

Private users, as well as companies and the public sector, will all benefit from the digital transformation of the road 
infrastructures. The Smart Road will allow a proactive adoption of technology embedded within the road infrastructure, improving resiliency and optimizing infrastructure management. New digital technologies, indeed, allow to gather a huge amount of data on the status of road infrastructure and traffic density, data that are available to road management companies, users and service providers. The way this data will be treated and managed is at the basis of the offering of new and innovative services to the users. Road infrastructure embedded with digital technologies, furthermore, are of great relevance to the monitoring activities of the territory, since such infrastructures cover in a capillary way all the territory, and hence allow a massive flow of information on their networks. This, though, requires a high level of convergence between the road infrastructure and the information flow, and a holistic approach to the data management, at local and national level.

Moreover, a higher level of automation and connectivity of the road infrastructure thanks to the adoption of sensors and other devices, including cars, will increase the overall level of safety on the roads, due to a continuous monitoring of physical infrastructures such as bridges, tunnels and other relevant infrastructures, which will allow predictive maintenance rather than traditional maintenance, increase effectiveness and efficiency of roads' maintenance services.

The contemporary attention to the road infrastructure and the vehicle flow on the roads will allow a more "shock resistant" mobility; therefore, smart road will be characterized by technologies, functionalities and services offered that will generally improve the operational costs, the overall maintenance status of the road infrastructure, increasing the resiliency of the infrastructure itself.

Furthermore, leveraging on the information collected on the roads, it will be possible to provide some services, in real time, directed to the digital devices installed on boards of cars, or directly to the smartphones of the car passengers. More services are expected, related to predictive navigation functionalities and to the possibility of detecting and monitoring the transportation of hazardous materials.

Other services that will be possible to offer to the companies that manage the road infrastructure are related to the improvement of the maintenance standard and quality, as well to the traffic and mobility management. Just few examples to understand the potential of such services: the quality of the road surface, the stress level of the road infrastructure, the quality of the barriers and fences around the road infrastructures, all this allowing a predictive maintenance of the infrastructure; as well as the weather conditions on the roads, allowing a more effective snow removal and assistance in case of severe and adverse weather conditions.

For final users, all the advantages deriving from an improved mobility, both at urban and extra-urban level, are related to a better mobility, an increased level of road safety and a lower rate of cars crashes, and an overall increased quality of the road infrastructure, which allows the data flow relevant to the mobility as well as to the monitoring activity of the environment, the infrastructure status and the flow of vehicles.
For companies, expected benefits are both direct and indirect. Among the direct ones, it is important to mention the effective monitoring of the goods transported on trucks, increasing the overall efficiency of road transportation; among the indirect ones, the possibility to open a new market related to all the devices, sensors and digital solutions helping the commercial transportation sector. The latter would generate high revenues for all the parties involved in the ideation and production of services related to the mobility, which in general are recognized as high value-added services.

\section{ApPliCATIONS OF SMART ROAD CONCEPT}

\section{A. Hamburg Smart Road}

The first location in Europe for "smart road testing" is located in Hamburg (Germany). The smart road is the result of an agreement signed between the City of Hamburg and Cisco in April 2014 [33]. Other partners involved include Philips, for lighting technology, AGT International for analytics and Kiwi, for video analytics and anonymization. The roadway took four months to build near Hamburg's docks and the road links three streets and the Kattwykbrucke Bridge (Fig. 2).

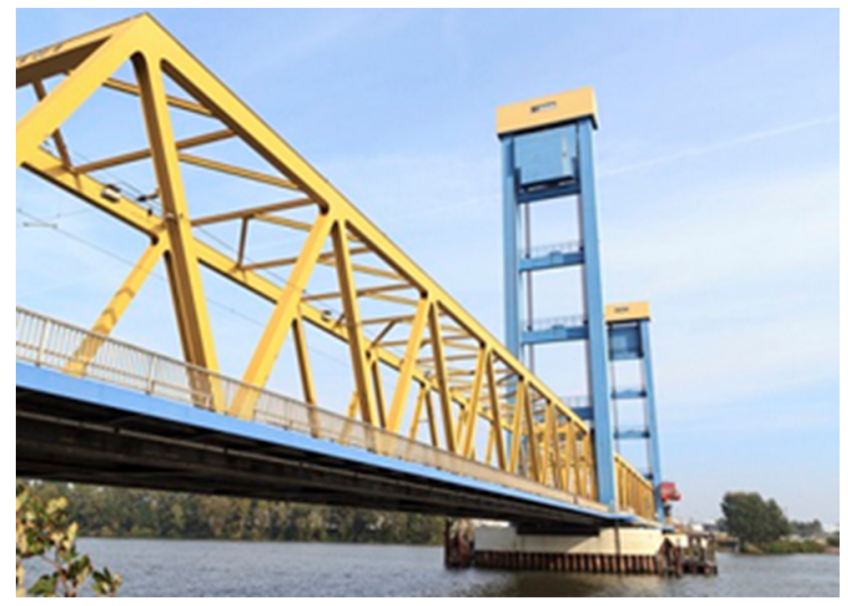

Fig. 2. Kattwykbrucke Bridge in Hamburg [33].

The road opened in May 2015 and it is festooned with cameras and sensors mounted to light poles along the road. The four components that make the road smart are:

- Smart Traffic Management. This helps the port road manager to monitor road traffic. In particular, the incidents are detected automatically, and the manager is alerted to coordinate with other authorities.

- Smart Structural Sensors that provide real time data on the condition of movable infrastructures.

- Smart Environmental Sensors delivering data that is used to improve analysis of the environmental situation in the area.

- Smart Lighting that enhances safety for pedestrians and cyclists in the port and saves energy at the same time.

All sensors and systems involved in this project are connected by a highly secure network infrastructure. Data is processed by analytics software, and findings are made available via a 
centralized, integrated dashboard. The smart road has been tested until April 2016 [33].

\section{B. Photovoltaic Pavement}

Photovoltaic pavement enables energy generation by using PV. Different locations can be candidate for the use of this technology, such as parking lots, foot paths, driveways, streets and highways [34 - 37]. SolaRoad is a system being developed by the Netherlands Organisation for Applied Scientific Research (TNO), the Ooms Groep. They plan to install their panels on 100 $m$ of cycle path in Krommenie, Netherlands in November 2014. The Solar Roadways company of Idaho, USA, is developing a prototype system to replace current roads, parking lots, and driveways with photovoltaic solar road panels that generate electricity. Another country, South Korea has built a freeway with the median covered by solar panels above a bikepath. The first photovoltaic road in the world was constructed in Tourouvre, Orne, France in 2016 (Fig. 3) [38].

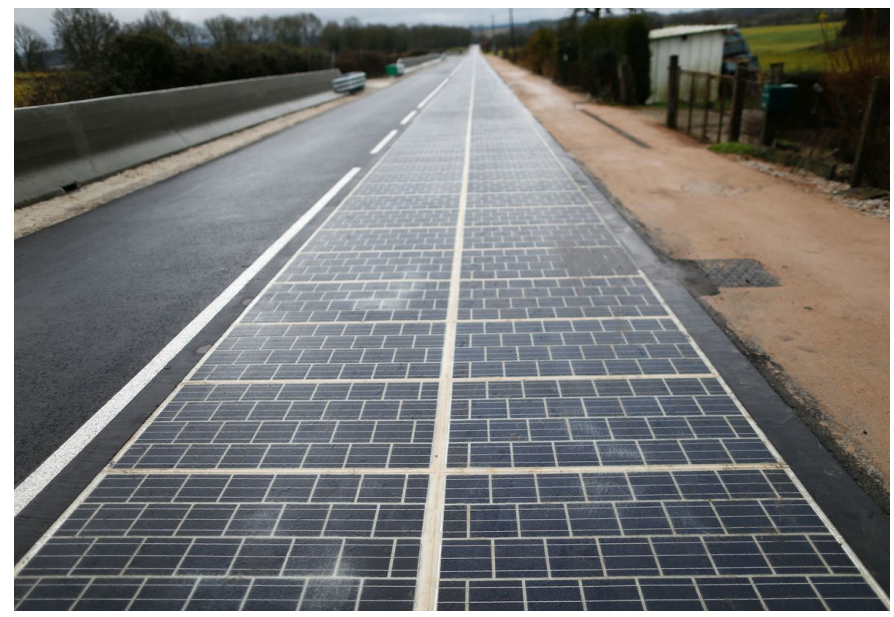

Fig. 3. Photovoltaic road in France [38].

\section{Solar Road Panels}

The scope of use of solar roadways is to replace asphalt roads with Solar Panels which generate energy through the sun that can be used by local houses or businesses that are connected to the system from either the house's driveway or the businesses parking lot $[39,40]$. The panels will also increase the number of charging stations for electric cars if that station is connected to the solar roadway. Each panel have their own LED lights that will be used as the road lines. There are 3 layers that make up the solar panels:

1. The Road Layer is the High Strength layer that has the photovoltaic cells which attracts the sun's rays, it has traction, so vehicles do not slide of the road, and it is waterproof to protect the layers below.

2. The Electronic Layers contain a mini microprocessor board that helps control the heating element of the panels; this technology can help melt the snow that lands on the panels so that hazardous road conditions will no longer be an issue in the more northern regions. This layer can sense how much weight is on the panels and can control the heating element to melt the snow.
3. The Base Plate Layer is the layer that collects the energy from the sun and distributes the power to the homes or businesses that are connected to the solar roadways. This will also be used to transfer the energy to cars as they drive over the strip to recharge the battery.

\section{Smart Pavement}

The Missouri Department of Transportation (MoDOT) began testing out "smart pavement" at a rest stop outside of Conway, Missouri late in 2016. The pilot program currently covers about 200 square feet of sidewalk at the visitor center. In this study, the panels will heat the road and keep snow and ice from accumulating. They will also feature LED diodes that will increase the visibility of road lines (Fig. 4).

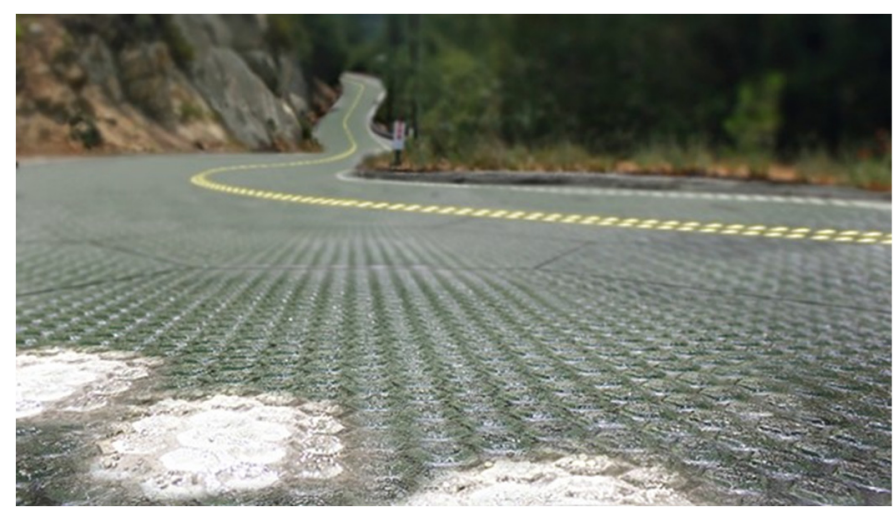

Fig. 4. Smart Pavement [41].

\section{E. Electric road}

In Sweden, Scania's new heavy trucks are equipped with a pantograph mounted behind the driver's cab, which is connected to the truck's regular propulsion system (Fig. 5). The function of the pantograph on the roof of the truck is to feed the electricity to an electric hybrid system. It is able to connect automatically at speeds of up to $90 \mathrm{~km} / \mathrm{h}$. When the truck leaves the electrical network, it returns to its diesel hybrid mode [42].

The pantographs get their power from the electric cable line above the road with the designated lane kept separated from other driving lanes. It is equipped with poles, holding up electricity cables in the right driving lane and they are protected by a railing.

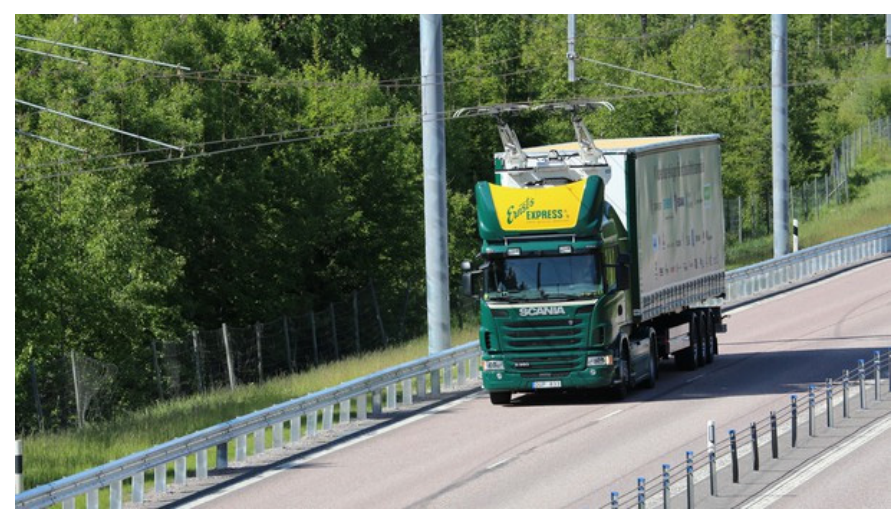

Fig. 5. Scania's truck being powered via overhead electricity lines [42]. 


\section{F. Photo-Luminescent road marking}

The Smart Highway is based on the incorporation of a photoluminescent paint for road signs, which absorb light during the day and light up for up to 10 hours. This is a new concept of signage applied to the highway. This technology is developed by Studio Roosegaarde and the Heijmans infrastructure management group in the Netherlands. Figure 6 represents a stretch of motorway in Brabant, the Netherlands [43] where it has adopted these new markers.

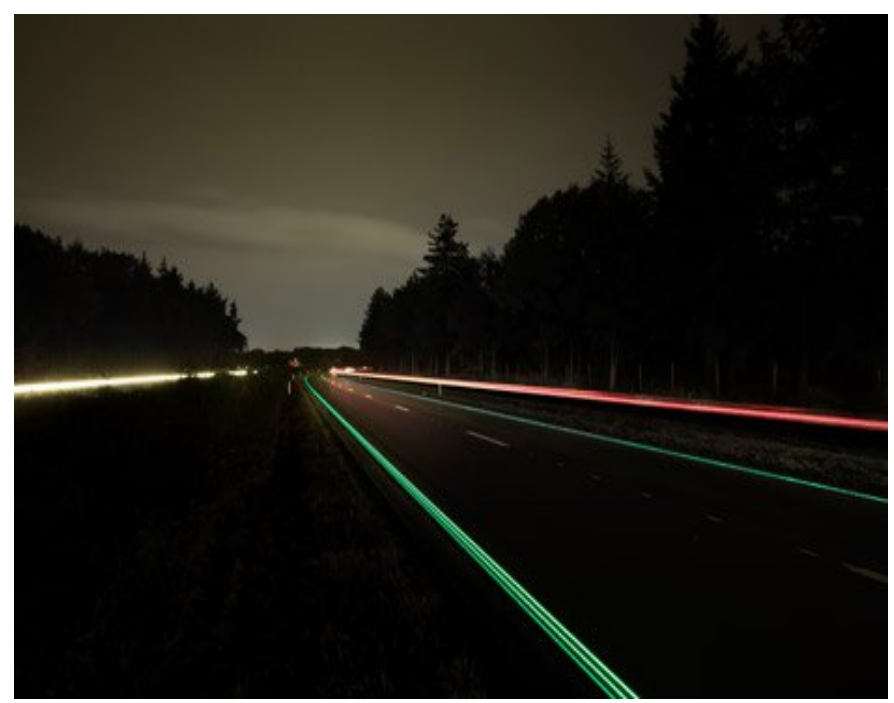

Fig. 6. Road marking glowing in the dark [43].

\section{CONCLUSIONS}

Despite the huge proliferation of regulations and laws, the targets set forth at European level regarding the ITS are far from being achieved in Italy, and the examples above illustrated are still missing in the Italian road infrastructure system.

Looking at the regulatory side, notwithstanding some specific regulation, e.g. (i) DB CCISS (open data on the infrastructure and traffic congestion flow); (ii) Public index of the information related to Infrastructure and traffic; (iii) the adoption of the protocol DATEX-II and the necessity to introduce a systems of nodes DATEX-II; (iv) the legal requirement for authorities to keep data center with all the information relevant to the infrastructure, still several criticalities can be envisaged: first of all, the majority of the requirements of the Decree no. 446/2014 have not been enforced yet, together with a lack of governance of the migration to the ITS. It is therefore urgent to proceed shortly to the definition of the technological standard required to transfer at Italian level the requirements of the European directive. This would enable to overcome the inertia generated at national level, at least in Italy, shedding light on the functions and services enabled by the diffusion of Smart Road and defining, in a clear way, the specifications needed to allow the diffusion and the deployment of the digital transformation of the road infrastructure. The achievements of such objectives shall be obtained through four main strategies:

1. Agile, shared and useful infrastructures, with an improved engineering and construction phase. This goal will be achieved, in the medium term, through the innovation introduced in the planning, engineering and construction phases of new infrastructures;

2. Modal and intermodal integration of the different transportation means, which means moving towards a sustainable transportation system, with a proper equilibrium between road and railway transportation, especially for goods delivery and logistic services;

3. Sustainable Urban Development, through integrated projects of urban mobility which connect the metropolitan areas to suburban ones, especially for commuting users;

4. Increase safety and security of the existing infrastructure, in line with the already approved maintenance and improvement programs of intervention.

The smart Road initiatives here discussed belong to the point 4) mentioned above, with the goal to increase the safety and quality standard of the transportation infrastructure, ensuring reliability of the maintenance program in place, through specific actions to implement digital technologies and solutions inside the current maintenance interventions. The digital transformation of the transportation infrastructure, indeed, shall increase the chance to create value to the users, i.e. the citizens, for companies and for all the actors of the value chain that may provide services related to the commercial offer of digital solutions for a smart mobility. This would allow the creation of an extended customer experience, towards a future where sensors, digital devices and web platforms will allow a better management of the overall transportation infrastructure, new business models and new services for the community of users of the infrastructure itself, fostering the economic growth of the Country.

\section{REFERENCES}

[1] Y. J. M. a. I. S. S. J. Kim, "Smart Mobility Strategy in Korea on Sustainability, Safety and Efficiency Toward 2025," IEEE Intelligent Transportation Systems Magazine, vol. vol. 7, no. no. 4, pp. pp. 58-67, 2015.

[2] H. O. a. P. L. Correia, "Automatic road crack detection and characterization," IEEE Transactions on Intelligent Transportation Systems, pp. pp.155-168, 2013.

[3] C. K. a. I. Brilakis, "Pothole detection in asphalt pavement images," Advanced Engineering Informatics, pp. pp. 507-515, 2011.

[4] S. C. K. J. R. C. a. C. H. L. Y. H. Tseng, "Strategies for autonomous robots to inspect pavement distresses," Automation in Construction, pp. pp. 1156-1172, 2011.

[5] X. Y. a. E. Salari, "Pavement pothole detection and severity measurement using laser imaging," IEEE International Conference on Electro/Information Technology, pp. pp. 1-5, 2011.

[6] B. G. R. D. M. B. a. M. C. M. Fazeen, "Safe driving using mobile phones," IEEETransactions on Intelligent Transportation Systems, pp. pp. 14621468, 2012.

[7] P. Mohan, V. Padmanabhan and R. Ramjee, "Nericell: rich monitoring of road and traffic conditions using mobile smartphones," ACM conference on Embedded network sensor systems, pp. 323-336, 2008.

[8] V. Astarita, M. Caruso, G. Danieli, D. Festa, V. Giofrè, T. Iuele and R. Vaiana, "A mobile application for road surfacequality control: UNIquALroad," Procedia-Social and Behavioral Sciences, pp. 11351144, 2012.

[9] F. M. S. M. a. E. Z. A. Cigada, "Lasertriangulation device for in-line measurement of road texture at medium and high speed," Mechanical Systems and Signal Processing, pp. pp. 2225-2234, 2010. 
[10] F. J. N. G. C. Blanco, "An efficient multiple object detection and tracking framework for automatic counting and video surveillance applications," IEEE Trans. Consum. Electron, p. 857-862, 2012.

[11] Congress, N. (1996). Smart Road, Smart Car: The Automated Highway System. Public Roads, 60(2).

[12] De La Peña, E. (2015). Smart Road, A Vision. Smart Transportation Alliance, 2015.

[13] G. B. R. M. Z. Sun, "On-road vehicle detection: a review,” IEEE Trans. Pattern Anal. Mach. Intell, p. 694-711, 2006.

[14] C. Y. Y. C. Hai Wang, "Smart road vehicle sensing system based on monocular vision," International Journal for Light and Electron Optics, vol. 126, pp. 386-390, 2015.

[15] X. a. E.Salari, "Pavement pothole detection and severity measurement using laser imaging," IEEE INTERNATIONAL CONFERENCE ON ELECTRO/INFORMATION TECHNOLOGY, pp. 1-5, 2011.

[16] F. O. a. P. E. Eren, "Road hazard detection and sharing with multimodal sensor analysis on smartphones," IEEE International Conference on Next Generation Mobile Apps, pp. 56-61, 2013.

[17] Y. Hsu, J. W. Perng and Z. WU, "Design and implementation of an intelligent detection system with multisensors integration," International Conference on Machine Learning and Cybernetics (ICMLC), pp. 219225, 2016.

[18] S. Chu and A. Majumdar, "Opportunities and challenges for a sustainable energy future,” Nature, vol. 488, pp. 294-303, Aug. 2012.

[19] Ziarmand, A., Kucherenko, D. \& Soklakova, T. (2016). Transport monitoring and control systems, East-West Design \& Test Symposium (EWDTS). 2016 IEEE, pp. 1-4, 2016, ISSN 2472-761X.

[20] "Photovoltaic (PV) pricing trends: historical, recent, and near-term projections," National Renewable Energy Laboratory, 2012.

[21] B. Elsinga and W. Van Sark, "Spatial power fluctuation correlations in urban rooftop photovoltaic systems," 2014.

[22] N. Reich, B. Mueller, A. Armbruster, W. Sark, K. Kiefer and C. Reise, "Performance ratio revisited: is PR $>90 \%$ realistic?," Prog Photovolt: Res Appl 2012.

[23] W. S. P. Goli, "PV powered smart charging station for PHEVs," Renewable Energy, vol. Volume 66, no. ISSN 0960-1481, pp. Pages 280287, 2014.

[24] P. B. M. Z. G.R. Chandra Mouli, "System design for a solar powered electric vehicle charging station for workplaces," Applied Energy, vol. Volume 168, no. ISSN0306-2619, pp. Pages 434-443, 2016.

[25] G. Chandra Mouli, P. Bauer, T. Wijekoon, A. Panosian and E. Barthlein, "Design of a power-electronic-assisted OLTC for grid voltage regulation,” IEEE Trans Power Delivery, Vols. 30:1086-95, 2015.

[26] M. Singh, K. Thirugnanam, P. Kumar, P. Kar and I. Kar, "Real-time coordination of electric vehicles to support the grid at the distribution substation level," IEEE Syst J, Vols. 9:1000-10, 2015.

[27] K. Thirugnanam, J. Ezhil Reena, M. Singh and P. Kumar, "Mathematical modeling of Li-ion battery using genetic algorithm approach for V2G applications," IEEE Trans Energy Convers, Vols. 29:332-43, 2014.

[28] R. Das, K. Thirugnanam, P. Kumar, R. Lavudiya and M. Singh, "Mathematical modeling for economic evaluation of electric vehicle to smart grid interaction," IEEE Trans Smart Grid, Vols. 5:712-21, 2014.

[29] K. Thirugnanam, T. Joy, M. Singh and P. Kumar, "Modeling and control of contactless based smart charging station in V2G scenario," IEEE Trans Smart Grid, Vols. 5:337-48, 2014.

[30] G. Preetham and W. Shireen, "Photovoltaic charging station for PlugIn Hybrid Electric Vehicles in a smart grid environment," IEEE PES Innovative Smart Grid Technologies (ISGT), pp. 1-8, 2012.

[31] Zhao, H. \& Wu, D. (2015). Definition, Function, and Framework Construction of a Smart Road. International Symposium on Frontiers of Road and Airport Engineering October 26-28, 2015. Shanghai, China.

[32] European Commission. Mobility and Transport - Intelligent transport systems- Action Plan and Directive. Available to: https://ec.europa.eu/transport/themes/its/road/action_plan_en

[33] The first "Smart Road" exists in Hamburg. Availbale to: https://www.novascientia.net/articles/283/The-first-\%E2\%80\%9CSmartRoad\%E2\%80\%9D-exists-in-Hamburg
[34] A. Nagarajan and W. Shireen, "Grid connected residential photovoltaic energy systems with Plug-In Hybrid electric Vehicles (PHEV) as energy storage," IEEE PES General Meeting, pp. 1-5, 2010.

[35] J. Zhao, S. Kucuksari, E. Mazhari and Y. Son, "Integrated analysis of high-penetration PV and PHEV with energy storage and demand response," Appl. Energy, vol. 112, pp. 35-51, Dec. 2013.

[36] T. K. S. M. a. L. K. S. Z. Hassan, “A Road to Wind Based PHEVs Smart Charging Station," 2015 13th International Conference on Frontiers of Information Technology (FIT), pp. pp. 41-46, 2015.

[37] V. Etacheri, R. Marom, R. Elazari, G. Salitra and D. Aurbach, "Challenges in the development of advanced Li-ion batteries: a review," Energy Environ. Sci., vol. 4, no. 9, p. 32433262, Aug 2011.

[38] Photovoltaic paviment. Available to: http://www.skyscrapercity.com/showthread.php?t=490597\&page=177

[39] Solar road panels. Availabe to: http://www.solarroadways.com/

[40] World's first solar panel road opens in Normandy village. Available to: https://www.theguardian.com/environment/2016/dec/22/solar-panelroad-tourouvre-au-perche-normandy

[41] France to pave $1,000 \mathrm{~km}$ of road with solar panels. Available to: http://www.globalconstructionreview.com/trends/france-pa7ve-1000kmro7ad-so7lar-pane17s/

[42] Sweden becomes first nation to open electric highway that powers trucks using overhead lines. Available to https://www.techspot.com/news/65317-sweden-becomes-first-nationopen-electric-motorway-powers.html

[43] First highway with glow-in-the-dark markings opens in the Netherlands. Available to: https://newatlas.com/smart-highway-glowing-lines/34363/ 